\title{
Dimensões da Pesca na Comunidade Quilombola de Mangueiras (Illha do Marajó, Pará): características, conhecimentos tradicionais e cosmologias
}

\author{
Anael Souza Nascimento ${ }^{a}$ \\ Flávio Bezerra Barros ${ }^{b}$
}

Resumo: Este trabalho foi desenvolvido na comunidade quilombola de Mangueiras, Ilha do Marajó (Pará), com o objetivo de caracterizar os recursos pesqueiros de importância alimentar e as práticas utilizadas na pesca artesanal, bem como as sociabilidades que envolvem essa atividade e ainda, evidenciar o domínio cultural da comunidade sobre a pesca. Entrevistamos 21 pescadoras e pescadores para a elaboração da lista livre dos peixes. Empregamos entrevistas abertas e semiestruturadas, observação participante, turnês guiadas por pescadores locais e a técnica da listagem livre. Para análise da lista livre usamos o índice de saliência de Smith. Os resultados evidenciaram que os pescadores e pescadoras mantêm uma constante transmissão de conhecimentos, propiciada através do contato cotidiano com os peixes e com o rio desde a infância. O conhecimento tradicional faz parte da identidade e cultura do quilombo, território dominado por atores sociais conhecedores contumazes da ictiofauna, distinguindo-a por seu habitat, preferências alimentares e comportamentos.

Palavras-chave: Sociobiodiversidade, Pesca artesanal, Povos tradicionais, Cultura, Amazônia.

A pesca artesanal é considerada uma atividade muito antiga exercida pelos humanos. E esse tipo de atividade oportunizou aos pesca-

a Doutoranda em Agriculturas Amazônicas (Ineaf-UFPA). Email: eng.anael@ gmail.com.

b Professor Associado nos Programas de Pós-Graduacão em Antropologia (IFCHUFPA) e Agriculturas Amazônicas (Ineaf-UFPA).Email: flaviobb@ufpa.br. 
dores uma série de conhecimentos relacionados ao comportamento das espécies capturadas, desde a sua reprodução, alimentação e a localização e concentração de cardumes. $\mathrm{O}$ conhecimento adquirido pelos pescadores, sejam estes artesanais ou industriais, deve ser levado em consideração (Diegues 2004).

Segundo Furtado (2006), a pesca artesanal pode ser interpretada como uma expressão que supera o ato de pescar, uma vez que define um modo de vida e não apenas uma característica local e ocupacional. Assim, para entender uma sociedade pesqueira atual, faz-se necessário buscar as origens das mais diferentes sociedades e culturas que formaram a Amazônia; é preciso que esse resgate seja feito para assim entender o presente.

De acordo com Marques (1991), as comunidades costumam praticar a atividade da pesca no turno da noite, fazendo uso, em sua grande maioria, de iscas vivas, quando a atividade é realizada em locais mais profundos. Mas, para que se tenha sucesso na atividade, é preciso que os pescadores detenham um conhecimento sobre o comportamento e a cadeia trófica dos recursos pesqueiros.

Arruda et al (2018) destacam que, durante a pescaria, são compartilhadas informações e técnicas; assim, os pescadores conseguem manter uma interação que contribui para a manutenção dos conhecimentos, como se observou também no Riozinho do Anfríso, no Pará, aonde, além de conhecimentos, compartilham também instrumentos caracterizando-se como uma prática cultural de reciprocidade (Barros 2012). A pescaria costuma ser realizada por grupos e possui pescadores de diferentes idades que detêm um alto conhecimento sobre a cadeia trófica, como detalhado por Diegues (1988), Costa-Neto (2000), Clauzet et al (2005), Arruda et al (2018), Diegues (2004), Berkes et al (1995), entre muitos outros autores. O texto descreve diversos aspectos do conhecimento tradicional dos pescadores e as múltiplas estratégias e técnicas do manejo e conservação da biodiversidade envolvidos. 


\section{Área de estudo e métodos}

O estudo foi realizado no quilombo de Mangueiras, situado no município de Salvaterra, Ilha do Marajó, Estado do Pará (“00॰ 45” 12” S 48 31' 00” W). A localidade pertence à mesorregião de Marajó e à microrregião do Arari. É considerada a maior ilha flúvio-marítima do mundo, sendo formada por várias ilhas, totalizando uma extensão de aproximadamente $50 \mathrm{mil} \mathrm{m}^{2}$. O território marajoara possui 16 municípios, sendo Soure e Salvaterra os mais populares e mais próximos da capital do Pará, Belém (Brasil 2007).

A metodologia utilizada partiu de um estudo descritivo quantiqualitativo (Brumer et al 2008). Conduzimos entrevistas semiestruturadas (Bernard 1988) com ou sem o uso do gravador. Desse modo, a metodologia abordou a Etnoecologia com a perspectiva da interdisciplinaridade entre as ciências sociais e naturais para que assim se consiga compreender as inter-relações entre as sociedades humanas e o ambiente natural (Toledo 1992; Toledo \& Barrera-Bassols 2009). Para acessar informações referentes aos saberes e práticas da pesca artesanal nas comunidades quilombolas, apoiamo-nos na observação participante (Geertz 1989). O uso deste método permitiu acompanhar o trabalho das pessoas na comunidade na busca pela obtenção dos alimentos. Assim, os pesquisadores puderam residir com o grupo social estudado através de uma vivência real dos acontecimentos, a fim de compreender as dinâmicas do lugar, bem como as relações sociais e ambientais existentes.

Para a seleção dos interlocutores e grupos focais adotamos alguns critérios como as relações que essas pessoas possuem com o recurso pesqueiro, se pescam com a finalidade de subsistência ou para venda, qual a organização do trabalho no contexto familiar, se exerce alguma atividade de preparo ou venda de peixes e mariscos levando em consideração que o grupo doméstico possui disposição em seus respectivos trabalhos e como ocorre a reprodução de sociabilidade e reciprocidade. Também consideramos que os interlocutores deveriam ter um tempo de pesca igual ou superior a 25 anos. 
A amostragem utilizada nesses casos contou com a participação de pescadores, marisqueiros e pessoas envolvidas com a pesca na área. A indicação das espécies de peixes e mariscos conhecidos foi realizada por meio da técnica de Lista Livre (free list), que parte do princípio de que as espécies mais citadas e colocadas nas primeiras posições da lista são aquelas que possuem uma maior importância cultural (Albuquerque et al. 2010). A partir dos dados da lista livre e auxílio do software Anthropac (versão 1.0.2.60), foi calculado o Índice de Saliência Cultural (Smith 1993), que varia entre 0 e 1 e, quanto mais próximo de um, maior a presença do elemento analisado no domínio da cultura, ou seja, os mais citados e lembrados pelos interlocutores.

Para o escalonamento multidimensional, calculamos os dados estatísticos a partir do programa Past statistic. Conforme Romney \& Weller (1984), através de representações gráficas, é possível evidenciar as similaridades, assim como o distanciamento dos entrevistados, com base nas respostas dadas. Para Romney \& Weller, "[...] indivíduos mais parecidos ficam próximos no centro da imagem e, menos parecidos, separados pela periferia da imagem" (1984:73).

\section{Caracterização do ambiente local}

Os tipos de ambientes que predominam na comunidade quilombola de Mangueiras são mangues, igapós e campos inundados com algumas partes da comunidade periodicamente inundadas pelas águas. O rio que circunda toda a comunidade é chamado de Rio Paracauari ou também conhecido como Rio Mangueiras (Figura 1). É um ecossistema que possui um tipo de floresta inundada em algumas partes, e também existe a formação de pequenas ilhas, onde geralmente são montados os acampamentos de pesca.

Existe uma variação sazonal influenciada diretamente pelos níveis de água dos rios e lagos que nos mostra dois momentos distintos e característicos da comunidade: a- quando ocorre o inverno amazônico, período de cheias e inundações iniciando em janeiro e indo até junho. Nessa época o regime de chuvas costuma ser maior, e pode 


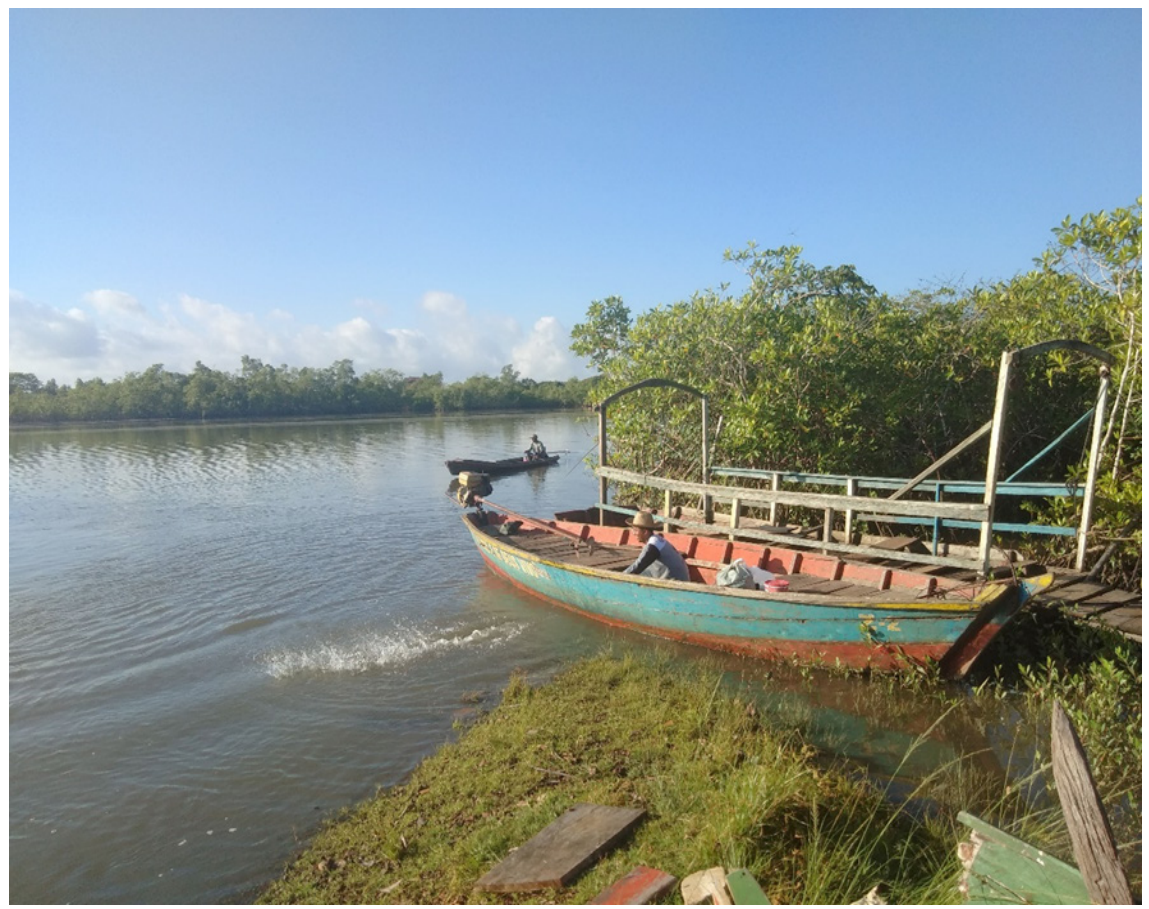

Figura 1: Rio Paracauari, Salvaterra/PA. Foto: Anael S. Nascimento.

oscilar e variar um pouco nos meses de ano-a-ano e b- momento do verão amazônico, quando se observa a temporada seca, e ocorre nos meses de julho a dezembro, com a incidência de chuvas diminuindo gradativamente e os rios começando a baixar os níveis de água e em algumas partes próximas da comunidade começa-se a ter acesso aos lagos que são formados nesse período e que os quilombolas utilizam para a pesca dentro de uma característica sazonal a partir da ideia de Farias (2001). Esse tipo de conhecimento é determinante na escolha de que técnicas e estratégias serão utilizadas para se obter maior eficiência (Diegues 1983, 1995; Begossi 1992; Silvano 1997).

A sazonalidade influencia diretamente no ritmo de vida social destes quilombolas e as atividades que são executadas obedecem aos fenô- 
menos ambientais presentes nesses dois momentos que marcam as vidas dos mangueirenses. Alencar (2014), em seus estudos na RDS Mamirauá, onde a sazonalidade também influencia consideravelmente no calendário de atividades pesqueiras das famílias nesta parte do Amazonas.

Assim como descreveram Ramires et al (2007) em suas investigações, os pescadores diferenciam as épocas do ano em verão e inverno, além de também destacarem a sazonalidade no que se refere a captura de determinados peixes, como por exemplo, o pescado do verão (sarapó, piranha, traíra, aracu, mandubé, jiju), o pescado do inverno (cachorrinho do padre, carataí, cangatá, dourada) e o pescado do ano inteiro (bacu, bagre, filhote, tambaqui). Nas épocas que cada tipo de peixe tenha sido bem observado também se notou algumas oscilações quanto ao período opinado pelos quilombolas sobre o aparecimento dos peixes. Autores como Costa-Neto \& Marques (2000) também evidenciaram essa diferença que os pescadores fazem de acordo com a estação do ano.

Abaixo segue um relato da captura de filhote (um tipo de peixe) em lua nova. Os pescadores foram até próximo a uma fazenda na expectativa de pescar esse peixe.

Eu fui atrás do filhote, eu não te falei que hoje era um dia bom, em dia de lua é bom aproveitar, pode ter sorte. Eu fui com um parceiro pra iscar a linha, mas como tava muita chuva, fomos logo olhar a rede, a maré já tava dobrando de vazar, aí ele disse assim, bora colher a rede. Mas não demorou, ele disse: me ajuda, me ajuda que é um filhote [...], ai eu fui pra lá ajudar, ele [filhote] deu uma porrada que tirou a rede das nossas mãos, ele buiou com a rede na cara, eu enxerguei ele, tava com a cabeça pra cima e o rabo pra baixo, ai eu dei um nó de forca, ai eu segurei na rede e no cabo que eu tinha dado nó de forca e dei com um ferro na cabeça dele, ele amolestrou e virou de peito pra cima, ai nós embarquemos. (Fabiano, 45 anos).

Os períodos lunares são norteadores para os pescadores e muitas vezes determinam o sucesso ou o insucesso da pescaria. Contudo, constatamos que as fases da lua dizem respeito a facilidade e quantidade de captura de determinada espécie, ou seja, isso não significa dizer 
que só se pega peixe em luas. Pelo contrário, indica que certas espécies de peixes preferem determinadas fases lunares. Um bom exemplo é o filhote, comumente encontrado na lua nova, como pode ser observado na narrativa acima, quando os pescadores capturaram um filhote de aproximadamente $40 \mathrm{~kg}$ o qual foi vendido em Soure e o dinheiro da venda repartido em partes iguais. Para analisar a importância do entendimento dos períodos lunares para os pescadores, usamos como referência Costa-Neto \& Marques (2001).

A vegetação das margens dos rios é composta por açaizeiro, tucumanzeiro, coqueiro, inajazeiros, mas, sobretudo, mangueiros. Este último predomina em áreas que possuem intermediações com os terrenos lamacentos dos igarapés (furos) que se conectam aos rios. Os furos são uma forma de comunicação natural entre rios ou lagoas e também podem se chamar igarapés. $O$ mangal, então, se apresenta com uma vegetação densa e alagada e fica de um lado e do outro do rio, caracterizando a paisagem dos furos e muitas vezes essa vegetação serve para colocar as redes de um lado para o outro para aguardar o pescado. Em meio a estas paisagens também se tem uma floresta mais firme, na qual as inundações não são tão fortes e esses locais geralmente servem de acampamento aos pescadores, onde montam suas barracas, descansam, comem e param para conversar um pouco. À medida que se sobe o leito do rio, as modificações das paisagens das margens não são tantas, a não ser pela largura da foz e pela vegetação que pode ser mais densa e alta.

\section{No ritmo das marés}

A maré na comunidade de Mangueiras é importante e marca como se darão os deslocamentos para a pesca. Os fluxos e as intensidades das águas são comportamentos observados por todos da comunidade, que estão sempre perguntando ou falando a que horas enche ou vaza o rio. As marés estão relacionadas com componentes astronômicos, os quais influenciam na regularidade dos ciclos, sejam eles diários ou quinzenais; portanto, a observação das fases da lua 
também direciona a comunidade e, particularmente, os pescadores. Esse fato também pôde ser observado no trabalho de Souza (2004), no qual relata a importância que os pescadores artesanais atribuem às condições ambientais, visto que, para eles, o sucesso ou o fracasso da pescaria depende muito das fases da lua, das variações de maré e da presença ou ausência de chuvas.

As marés mortas ou águas mortas são as consideradas melhores para a pescaria de linha (espinhel) ou de rede, pois as águas não 'crescem tanto', facilitando a captura dos peixes, pois nesse momento os pescadores estão levando em consideração apenas o volume das águas. As marés vivas ou águas vivas, embora em alguns relatos termos constatado a fala de que nesse período seja difícil a pesca pelo aumento no volume das águas, há uma certa contradição quando neste mesmo período é comum se pescar o bagre, pois este peixe costuma boquejar ${ }^{1}$ em luas cheias e novas e nessas luas é possível perceber um aumento na atividade dos peixes, que é quando as águas crescem e consequentemente diminui a quantidade de peixes por espaço. Ainda considerando as águas vivas é importante destacar que nesse ritmo de maré fica oportuno para se pescar de tapagem ${ }^{2}$, uma vez que a maré enche e seca totalmente, possibilitando a despescagem do peixe, enquanto durante as águas mortas os igarapés que são tapados não secam totalmente, dificultando o processo.

\section{Conhecimentos ictiológicos tradicionais}

O sistema ao qual está associada a relação presa/predador é sempre aperfeiçoado por pescadores que estão em constantes observações e já possuem um conhecimento significativo sobre a ecologia dos peixes, além do que, muitos desses conhecimentos, como destaca Marques (1991), são ajustados com os conhecimentos ictiológicos da academia. É um sistema culturalmente adotado e que está interligado a uma organização socioespacial que estabelece regras para a exploração dos recursos e que fica predefinida acerca dos possíveis conflitos existentes nesses espaços. 
Estudos como estes são importantes, pois corroboram com trabalhos como os de Marques (1991), Begossi \& Figueiredo (1995), Paz $\&$ Begossi (1996), que também tratam dos conhecimentos ecológicos locais de pescadores e valorizam dessa forma as etnotaxonomias das comunidades. Nestas tabelas (ver Tabela 1) podemos verificar que a interação do ser humano com a natureza acarreta uma classificação específica e popular sobre a ecologia trófica e distribuição espaço-temporal, que foi adquirida e conhecida por conhecimentos tradicionais e científicos e que se baseia pelos preceitos propostos por Marques (2001) em 'Pescando pescadores', quando este compara os conhecimentos descritos pelos pescadores com o que está estabelecido na literatura acadêmica.

\title{
Citação dos pescadores e Citação da literatura pescadoras
}

\begin{abstract}
"O tucunaré come os matupirizinhos, insetos e camarão de perto dos galhos"

"A dieta de Cichlidae monoculus consistiu basicamente de quatro categorias principais: peixes, crustáceos, insetos e resíduos orgânicos" (Santos et al 2001:194).
\end{abstract}

"Sabe, o tucunaré ele é manhoso quando ta de filhotinho, ele não come de jeito nenhum, ele fica protegendo eles, ficam próximo do ninho né, tem que saber porque jogou a isca e se tiver manhoso, difícil pegar"

"Ele tucunaré é esperto, guarda os filhotes na boca, pra cuidar deles, a fêmea cuida bem dos filhotes".

"A família Cichlidae é composta por peixes que põem guarda aos ovos e filhotes" (Lowe-Mcconell 1975:89).

"Pacamu faz buraco na ribanceira, o acari, jiju também, eles fazem mais pra botar"

"O casal de tucunarés abriga a prole durante várias semanas" (Junk 1983:47).

"Batrachoides surinamensis é tipicamente encontrado em águas rasas salobras de ambientes estuarinos." (Garcia Jr. 2017:3). 
"O tamuatá é peixe de lama, ele gosta de tá enterrado lá, é muito fácil achar tamuatá na lama”

"Eu tenho curiosidade num peixe, eu nunca vi ele ovado, sabe qual é? É o bacu, não sei quando ele se reproduz, mas a gente tem ele o ano todo, eu tenho para mim que ele pari, porque não tem ova, a gente vê o bacuzinho mas de que forma ele tem, é sem explicação, a gente não vê nem filhozinho dentro"
"A sarda não é peixe de cabeceira, ela é peixe de baixa, ai a sardinha só sobe no período da comidia, ela é de baía."
"O tamboatá Hoplosternum littorale (Hancock, 1828), um siluriforme, predominante nas lagoas, que são ambientes rasos e ricos em macrófitas aquáticas." (Hahn et al 1997:57).

"Já a ecologia da reprodução da maioria dos Suliriformes da Amazônia é pouco conhecida. De acordo com a literatura, nunca se encontrou alevinos de Brachyplatystoma flavicans, B. vaillantii e Lithodoras dorsalis na Amazônia Central ou nas cabeceiras dos tributários que drenam os maciços do Brasil e das Guianas. A reprodução dessas espécies ainda é desconhecida e apesar de existir uma atividade pesqueira intensa, tanto no estuário quanto nas calhas principais dos rios da Bacia Amazônica, que explora essas espécies principais do gênero Brachyplatystoma, são raríssimos os indivíduos que são capturados ovados. Os registros de alevinos de Brachyplatystoma flavicans, B. vaillantii e Lithodoras dorsalis são os primeiros em toda Amazônia e sugerem que as espécies se reproduzem nas proximidades do estuário" (Goulding 1980:28).

"As migradoras como Hemiodus immaculatus, Hemiodus sp. 'microlepis longo', H. gracilis, Hypophtalmus edentatus, Potamorhina spp., Psectrogaster rutiloides, Pellona flavipinis, Semaprochilodus insignis, Semaprochilodus taeniurus e Cyphocharax abramoides, se agrupam em cardumes e realizam migrações longitudinais, rio acima, e\% ou migrações laterais dentro do lago Tupé, conforme as mudanças do nível d'água. Esses peixes desenvolvem parte do seu ciclo de vida no lago, durante a época de inundação, e outra parte no rio, na seca." (Bẻltrão \& Soares 2018:36) 
"No inverno dá uma grande comidia pra cá, dá o taperebá, ananin ai os peixes que gostam disso, vem tudo pra cá bem perto"

"A andiroba é bom demais pra pegar o tambaqui, é bom pegar eles nesses furos que tem andirobeira, quando cai um ele come"

"Não sei se seja mito, eu realmente não sei por que o jiju menstrua igual a mulher. Todo mundo diz que é, tem um período que se vê, várias pessoas já pegaram o peixe menstruado, quando pega ele nesse período ele sai sangue, aí por isso a gente diz que ele menstrua. Quando pega a fêmea já dá pra ver, aí o macho não, a fêmea tem o oveiro que o jiju bota, o macho não, ele tem tipo os testículos, e esse negócio é cheio de leite, dentro dele, é comprido e se cortar sai leite"

"Só que quando vem a chuva, o peixe sobe"

"O bagre ele choca os ovos dele, a fêmea bota e o macho choca, ele bota os ovos tudo na guelra e de lá já sai o peixinho da boca dele, agora não sei como é esse mistério que ele faz. Quando a gente pega o bagre macho, ele tá cheio de ovo na boca"
"Outros aspectos reconhecidos pelos pescadores, como movimento das marés, reproducãa, busca por alimento (comedia)" (Barboza \& Pezzuti 2011:137).

'Tambaqui procura seus alimentos em floresta inundada quando os frutos caem na água' (Goulding 1980; Sema 2010).

"O jeju é evitado porque tem a carne 'adocicada', 'sem gosto' e 'solta leite da toba' (o 'leite' foi descrito como o esperma do peixe que é liberado durante o período reprodutivo)" (Silva 2007:146).

"A migração ocorre no início da enchente, quando os cardumes de peixes caraciformes descem dos seus habitats nos rios afluentes[...]. A desova que ocorre geralmente entre dezembro e janeiro é do tipo sincrônico e total e requer perfeita adaptação aos ritmos do ciclo hidrológico" ('Sá Oliveira 2002:210)

Na região bragantina, já foi registrado o comportamento de cuidado parental dentre os bagres através da incubação de ovos (Krumme et al 2004). 
"O tamuatá ele bota mas é naquelas bolas de capim, ele choca também mas já é naquelas bolas de capim né e quando ta o ovo dele fica cheio de espuma, tipo para cobrir ou proteger os ovos e ele fica muito agressivo e geralmente isso é no seco, se tu passar ele te ataca"

"Tem um peixe baiacu aí, que a gente não come, porque ele tem tipo um veneno e faz mal, intoxica. Mas tem canto por aí que come né, acho que eles sabem tirar esse veneno"
"Na natureza, em época chuvosa, o tamoatá constrói um ninho flutuante em forma de concha, utilizando material vegetal morto, no qual deposita uma massa adesiva de ovos no lado escuro do ninho, em uma cama de espuma" (Miranda \& Crescêncio 2008:188).

"Das duas espécies de baiacus coletadas, apenas Colomesus sp. foi considerada comestível, mas somente se esta for tratada por especialistas, pois nem todos sabem como manejá-la" (CostaNeto 2009:123).

"O baiacu possui uma propriedade tóxica dos baiacus e deve-se à tetrodotoxina (TTX) e, bloqueadoras de canais de $\mathrm{Na}^{+}$dependentes de voltagem de nervos e músculos" (Oliveira \& Freitas 1996):49.

"O baiacu é geralmente evitado pelos moradores por não saberem limpá-lo ou manuseá-lo, também por ser um peixe considerado "venenoso" (Prado et al 2017:6).

Tabela 1. Conhecimentos tradicionais e conhecimentos acadêmicos sobre os recursos pesqueiros na comunidade quilombola de Mangueiras (Salvaterra/PA).

Dados de campo e de literatura.

Registramos 55 espécies de peixes, dentre estas 6 não são utilizadas na alimentação: lampreia, baiacu, poraquê, rebeca, tralhoto e o boto; os demais são consumidos e/ou comercializados na comunidade. Os interlocutores explicaram como concebem a ecologia das espécies, tal como pode ser identificado na narrativa de Cristina.

Esses peixinhos daqui a gente sabe tudo que come, esse tal de bacu come de tudo, mas ele gosta da florzinha de aninga, uma vermelhinha e do caramujo, ele adora. A gente sabe porque quando abre tá tudo na tripa. (Cristina, 45 anos). 
Dessa forma, é importante valorizar os estudos etnoecológicos para o conhecimento local da comunidade. Na perspectiva de Toledo (1992) e Nazarea (1999), a etnoecologia é um estudo capaz de agregar conhecimentos, estratégias, atitudes que possam englobar diferentes culturas e assim reproduzir conhecimentos acerca da existência social de um povo por meio de um manejo adequado de recursos naturais. Além disso, possui um enfoque teórico-metodológico que se concentra no estudo da relação ser humano-natureza e que apresenta a importância do papel do humano referente a sua cognição, se mostrando fundamental ferramenta no manejo, sustentabilidade e conservação dos recursos. Marques define os objetivos da etnoecologia como:

"O estudo das interações entre a humanidade e o resto da ecosfera, através da busca da compreensão dos sentimentos, comportamentos, conhecimentos e crenças a respeito da natureza, característicos de uma espécie biológica (Homo sapiens) altamente polimórfica, fenotipicamente plástica e ontogeneticamente dinâmica, cujas novas propriedades emergentes geram-lhe múltiplas descontinuidades com o resto da própria natureza. Sua ênfase, pois, deve ser na diversidade biocultural e o seu objetivo principal, a integração entre o conhecimento ecológico tradicional e o conhecimento ecológico científico" (Marques 2001:49).

Outro fator interessante na classificação e reconhecimento de espécies na comunidade de Mangueiras é que os interlocutores afirmam que um peixe pode ter mais de uma variedade pertencente a mesma espécie. Os interlocutores citaram exemplos como a piranha-branca, piranha-vermelha, dourada-branca, dourada-amarela, acari-espinhento, acari-boi, acari-muxinga, acari-branco, acari-chuteira, acará-folha, acará-branco, pescada-branca, pescada-amarela, pescada-preta, pescada-curuvina, pescada-cucuruta. Assim, também ocorre no trabalho de Ramires et al (2007), no qual os pescadores afirmam que os peixes, dependendo da espécie, possuem variedades. Neste caso, como não realizamos coleta de peixes e nem os identificamos sistematicamente, empregamos aqui o termo etnoespécies, no sentido de considerar a classificação folk, ou seja, nativa. Contudo, contamos com a colabora- 
ção de especialistas em ictiologia para, por meio das fotografias, descrições das características observadas e nomes locais, chegar ao que neste estudo denominamos de pista taxonômica. Trabalhos como os de Costa-Neto \& Marques (2000) mostram a verificação da etnoictiologia a partir da classificação de pescadores evidenciando que estes fazem uma hierarquia de espécies categorizando etnoespécies e etnofamílias.

De acordo com Ramires et al (2007), os pescadores costumam fazer a diferenciação do sexo do peixe através da ova. A literatura demonstra que dificilmente há características externas que podem apontar essa diferença entre macho e fêmea, sendo que as gônadas masculinas são reduzidas enquanto as femininas em fase de maturação conseguem ser vistas a olho nu e dessa forma permitir que se diferencie o sexo através dessa característica (Vazzoler 1996). Assim também ocorre na comunidade de Mangueiras, onde os pescadores conseguem fazer a distinção entre macho e fêmea através da ova, exceto com o tucunaré, pois este possui uma distinção anatômica externa, onde este peixe, em estágio de maturação sexual, possui um adorno protuberante de 'gordura' ou 'tutiço', localizado na parte dorsal próxima a cabeça, como é caracterizado pelos quilombolas; isso costuma ocorrer na época da reprodução. Outro ponto observado por eles nessa espécie é que os adultos em época de reprodução não se alimentam. Para 100\% dos pescadores e pescadoras entrevistados todos os peixes são diferenciados entre adultos e filhotes pelo seu tamanho.

\section{Pesca para comercialização e consumo}

Em relação a atividade desenvolvida pelos pescadores, existem alguns critérios como a definição do local que vão pescar de acordo com a finalidade que irão dar ao produto final. Se o recurso for para a subsistência, a pesca fica restrita aos lagos, rios e mangues próximos a sua residência, onde estão concentrados os 'peixes menores'. Mas se caso for para a venda, eles se organizam para ir pescar no Rio do Saco, distante de 4 a 5 horas da comunidade. No Rio do Saco estão con- 
centrados os 'peixes maiores', os quais são destinados na sua grande maioria para a comercialização. Para este local os homens costumam ir, pescar e vender diretamente para as geleiras que vêm buscar o peixe no local para comercializar em Salvaterra, Soure, Ponta de Pedras ou no Ver-o-Peso/ Belém.

Quando questionados sobre as formas de captura, preparo e consumo dos recursos pesqueiros, uma série de técnicas próprias foi evidenciada, destacando cada detalhe e com quem aprenderam as práticas. Mas o que nos chamou muito atenção foi o entusiasmo com que esses conhecimentos estavam sendo contados, repletos de simbolismo e memórias de como a comunidade já foi e vem sendo reconstruída.

Geralmente as mulheres pescam mais nos mangues. Elas relataram ser uma distração e uma diversão e que quando a 'parceira' não está não é a mesma coisa. Consegue pegar o caranguejo e o caramujo, mas falta algo. Em meio a essa situação também podemos observar esse fato no trabalho de Machado (2007), o qual mostra um pouco dessa invisibilidade do que é considerado trabalho nas áreas de manguezais, pois assim como ocorre em Mangueiras a pouca visibilidade se dá porque a coleta de crustáceos e mariscos não ocorre em áreas distantes ou de rio e também não está associada a peixes.

Em relação a comercialização de pescado e mariscos dentro da comunidade, esta é feita por crianças e jovens. Estes vendem o pescado em cambadas ${ }^{3}$ na comunidade tão logo os pais regressem da pesca e mariscagem. A venda também pode ser realizada na casa do próprio pescador. Essa comercialização apenas se dá caso o pescador/marisqueiro tiver excedente, pois no geral a pesca ou mariscagem é realizada para consumo.

\section{A organização do acampamento e das equipes de pesca}

O acampamento geralmente fica localizado em uma área mais alta, aonde os índices de alagamento não sejam tão elevados. Para construir a barraca/choupana é preciso antes retirar madeiras e varas e cortá-las de acordo com o tamanho que se deseja. Os grupos que 
ficam no acampamento iniciam um processo de montagem da barraca bem rápido. Para esse trabalho é necessário o uso de facões para cortar as madeiras na medida em que desejam e assim, após os cortes, fazem as amarras necessárias para fixarem bem a barraca.

A barraca possui um assoalho feito de madeira com tábuas corridas e encaixadas umas nas outras. Esse assoalho serve para quando ocorrer um alagamento na área, estes ficarem em cima e guardarem seus utensílios de trabalho e uso pessoal, como: redes, tarrafas, pente, escova, creme dental, etc. Esse assoalho também pode servir para o descanso diurno para aqueles que não levam redes. Neste caso, os pescadores se deitam por cima de um pano sobre o assoalho. A barraca conta com quatro ou mais esteios que apoiam a estrutura como um todo e em cima são colocadas travessas na qual são amarradas as redes de dormir.

Um dos cuidados que se deve ter no acampamento é com os gaviões, que a todo o momento tentam atacar os peixes que foram capturados pelos pescadores e que por vezes ficam expostos na montaria ou em alguma parte pegando sol para aqueles peixes que passaram um pouco do tempo de ser desmalhado; então, para que não estrague a carne, esse costuma ser salgado. É bem comum se ouvir dos pescadores "Aqui no acampamento tem que ter cuidado com os gaviões, eles são ladrões”, assim como no trabalho do Sautchuk (2007), que também mostra a indignação que os pescadores têm quando um gavião se atreve a 'tomar' o pescado, o que geralmente ocorre quando o pescado está exposto ao sol ou mal cobertos.

Os cuidados com os peixes são realizados às margens dos rios. Os peixes são às vezes descabeçados, mas em sua grande maioria, não, são eviscerados, e quando de escamas, descamados. Alguns peixes recebem vários lanhos, que nestes casos são cortes e outros recebem apenas um lanho longitudinal, em seguida é aplicado sal. Em alguns casos os peixes são apenas colocados no isopor.

Os pescadores dependem então dos familiares para executar as atividades, haja vista que é necessária uma organização de trabalho 
para se ter acesso aos recursos e aos territórios de pesca. As relações se dão através das noções de reciprocidade propostas por Sabourin (2008). Para referenciar sobre a necessidade de relações e organizações de trabalho acerca da pesca, se pode encontrar semelhança com o trabalho de Alonso-Población (2014), realizado na vila de pescadores de Saviño de Ningures, Espanha. O autor articula sobre os riscos e trabalhos entre os pescadores de uma cidade costeira. Dessa forma, também podemos encontrar relatos semelhantes pelos interlocutores de Mangueiras, que tratam da pesca que envolve riscos e muita imprevisibilidade e por isso essa rede de apoio está sempre se fortalecendo e se firmando através das relações com pai, filhos, irmãos, primos e sobrinhos.

Esse conjunto de relações se torna essencial, pois garante condições necessárias para que haja uma continuidade dessa atividade através das transferências de saberes das atividades de pesca. Nesse sentindo, os pescadores fabricam ou reparam/consertam suas redes, tarrafas, montarias, compram ou consertam lonas, ferramentas, mosquiteiros e preparam o material para a construção do acampamento.

Durante a pescaria, os grupos se organizam de modo que em cada montaria contenha dois pescadores, assim, enquanto um pilota, o outro fica com a responsabilidade de lançar a rede na água ou tarrafear se for o caso, para que estes consigam capturar os peixes. No trabalho de Alencar \& Sousa (2017), na Reserva de Desenvolvimento Sustentável Mamirauá, o mais experiente direciona a canoa para fazer um círculo com a rede e assim vai corrigindo quem está jogando a rede.

Os dois pescadores se auxiliam na ida a pesca, carregam para montaria os utensílios e instrumentos que precisam, abastecem a montaria e juntos a empurram para o rio. $\mathrm{O}$ que pilota então a direciona, quando desejam parar em algum lugar, fazem uso do remo para redirecionar a montaria; neste caso, os dois podem exercer essa função.

Há também pescadores que muitas vezes vão sozinhos para a pescaria, os quais necessitam fazer muito esforço, pois ficam responsáveis por executar as duas funções, a de piloto e a de lançador de rede ou 
tarrafa. Exercer essa atividade sozinho exige muita experiência, habilidade e força física.

Os riscos da pescaria são os mais variados possíveis como, por exemplo, quando a rede fica presa nos galhos das árvores, locais que estes costumam posicionar a rede já que muitos pescadores desejam capturar peixes encontrados nesses lugares, uma vez que os utilizam como moradia ou esconderijo contra predadores. $\mathrm{O}$ grande risco que ocorre é se o pescador não quiser perder a rede, este necessita mergulhar para soltá-la e isso torna propício o risco de encontrar jacaré ou mesmo outros perigos que os rios e lagos oferecem.

Os relatos sobre as temporadas no acampamento são regados de falas sobre abundância. Quando os pescadores vão para o Rio do Saco, costumam levar cachorros, alguns para "espantar as coisas ruins”, outros costumam levar para companhia, também levam cachorros novinhos, pois como ficam nas beiras dos rios e lagos sempre tem peixe 'sobrando' durante as refeições; então os cachorros novinhos são alimentados com muito peixe e leite, o que, segundo relatos, deixam eles fortes, com pelos bonitos, atribuindo esse fato a alimentação. Os cachorros se alimentam juntamente com os pescadores que a todo o momento lhes jogam pedaços de peixes durante as refeições.

\section{Conhecimentos e experiência na pescaria}

Para que a pesca seja eficiente o pescador ou pescadora deve deter conhecimento sobre a espécie-alvo que se deseja capturar, conhecer a dieta, habitat e a sazonalidade. Essas observações geralmente iniciam ainda na infância quando as crianças começam a acompanhar os pais ou os avôs nas jornadas. Dessa forma, a comunidade acaba estabelecendo um calendário anual e produtivo de quando e como as atividades ligadas a subsistência podem se manter e refletir nas decisões de pescarias e outras observações relativas em relação às marés, fases da lua, chuvas e demais fenômenos naturais. Nesse sentido, Murrieta (2001) classifica esses saberes como 'segredos de pescaria', os quais consistem justamente nesses conhecimentos acerca do meio. 
Com isso, os saberes são o resultado de um processo de construção de habilidades, práticas e interações com os animais e ambientes. A decisão de onde a pescaria será feita é geralmente avaliada por um conjunto de elementos como uma vegetação específica, abrigos das espécies, etc.

Considerando esses aspectos, os estudos etnobiológicos ou etnoecológicos representam uma ferramenta importante ao mostrar os aspectos científicos refletidos nos conhecimentos ecológicos locais das comunidades quilombolas que estreitam os laços que há entre as formas de saber sobre a natureza. Neste estudo se priorizou tratar a percepção dos quilombolas, relacionando-a com os conhecimentos acadêmicos por meio da perspectiva do diálogo de saberes.

A seguir alguns relatos que mostram o conhecimento dos pescadores artesanais referente ao comportamento das espécies-alvo, época do ano de reprodução, frequência de aparecimento e a preferência alimentar por espécie; esse conhecimento ecológico os favorece, pois aumenta as chances de captura. No conhecimento ecológico apresentado pelos pescadores jamais deve ser deixado de levar em consideração a relação que estes estabelecem com a natureza; isso faz com que haja uma boa gestão no uso dos recursos. É uma questão de modo de vida, são cosmologias, saberes e práticas locais que demarcam um valor e uma identidade.

'As fases da lua nesse período agora é mais filhote né, que ele é de lua né, pesca de lua, pesca de véspera dá pra pegar eles, até três dias depois da lua eles estão assanhados, sendo saída de lua eles se assanham. A piranha de cambada também é de lua. (Fabiano, 45 anos). A dourada a gente pega ela na bubuia ${ }^{4}$, bota a rede no rio né, espalha a rede no rio e bota uma alça de corda, não bota perto, é uma alça de corda em cada bóia. Ai ta vazando [explicações referentes à marél ela vai embora, ai quando a maré vem a gente pega ela na flor d'agua. (Fabiano, 45 anos).

Quando a noite é escura é o adequado pra pesca, prefiro pescar a noite, esses peixes vivem mais pra banda da cabeceira. (Elielson, 44 anos). Pra cá tem o aracu, e a gente nem pega ele no anzol, nem pensar porque para gente não dá de pegar assim. Aqui, tem a aninga, uma 
fruta, a gente cozinha ela e coloca no anzol pra pegar bacu, ele gosta muito, essas coisas a gente nunca termina de aprender, mas o bacu é um peixe que come quase tudo, come a manga, coco. (Elielson, 44 anos).

O conhecimento tradicional dos pescadores locais passa a ser moldado conforme o tempo, incorporando a manutenção da atividade da pesca acompanhando as principais transformações sociais e ecológicas sofridas no espaço e no decorrer do tempo. Quando o ambiente passa por uma situação de crise é preciso ter uma habilidade para entender essas alterações e se adequar, mantendo o conhecimento tradicional sempre em resiliência. É possível ver nos relatos dos interlocutores as mudanças no uso de instrumentos para pescar e as técnicas utilizadas a seguir.

Conforme o tempo foi passando vieram outro tipo de pesca e a antiga ela tá ficando mais difícil, porque de primeiro tinha uma tal de siririca, que era parecido um caniço, a gente amarrava uma pena de guará nela e saia puxando ela em cima d 'água assim para pegar tucunaré, de linha a gente não consegue mais distante, hoje em dia pode passar a siririca em cima d'agua que não pega, agora a gente só pega com isca artificial, o tucunaré não cai mais nessa. (Elielson, 44 anos).

Pra piranhar é bem simples, eles usam a capivara, porque dela tem o sangue né, então é só bater a capivara na água, e lá vem elas atacarem, ai joga o paneiro em cima e pronto. (Cristina, 45 anos).

\section{A pega}

Na comunidade de Mangueiras é bem marcante as paisagens de manguezais, que são as zonas úmidas entre o ambiente aquático e o terrestre. Essa zona de transição sofre influência direta do regime de marés, sendo ambiente de berçário para muitas espécies animais nas fases iniciais de vida, pois possuem alimentação e proteção adequadas ao desenvolvimento destes. Outra prática fundamental nessa comunidade, que as famílias chamam de 'pega', é a coleta do caranguejo, caramujo e turu. Em sua grande maioria esse tipo de extrativismo animal é praticado por mulheres e crianças que vão até os mangues, lagos 
e igarapés das proximidades praticarem tal atividade. Geralmente as mulheres vão acompanhadas de vizinhas e filhos.

A atividade marisqueira é tão tradicional quanto a pesca artesanal nesta comunidade, pois os quilombolas possuem um conhecimento ecológico tradicional importante sobre os manguezais. Esta prática inicia-se ainda na infância por volta dos oito anos quando as mulheres levam seus filhos para o mangue para pegar caranguejo, siri, sarará, caramujo e turu, todos são considerados importantes na dieta da comunidade em geral. Sendo que o sarará, um pequeno crustáceo, é utilizado no vinho, que na verdade é a polpa do fruto tucumã transformada em suco (consistente), pois os interlocutores acreditam que ao adicionar o sarará ao vinho fará com que este tenha uma melhor viscosidade e textura, considerada importante no prato cunhapira ${ }^{5}$.

Os turus são moluscos perfuradores de madeira e estão presentes nas mais diversas árvores do manguezal, como ananin, andirobeiras e mangueiro, no entanto, as interlocutoras afirmaram que os turus que estão presentes nas andirobeiras não são bons para consumo, pois têm um gosto mais amargo e por isso elas pegam apenas aqueles que estão nos mangueiros. Os turus desempenham um papel fundamental na deterioração da madeira, estes possuem um corpo gelatinoso e ficam seguros no mangueiro através de 'dentes', como denominam as mulheres apanhadoras de turus.

O camarão, embora seja um crustáceo, os quilombolas não classificam como pega ou coleta e sim, pesca. O crustáceo pode ser capturado por tarrafa, matapi ou pesca de tapagem, sendo esta última realizada com sacos de cebola (sacos de nylon de $60 \mathrm{~kg}$ ) e necessitando que no momento da captura, os pescadores tenham que deixar a água turva para conseguir fazer a pescaria com eficiência. $\bigcirc$ matapi é um apetrecho muito utilizado na pesca do camarão, em formato de cilindro e com uma pequena abertura na lateral. Nessa abertura são colocadas as iscas, que geralmente é farelo de coco e dessa forma eles são atraídos a entrar no matapi, depois de aguardar essa entrada é feita então a despescagem. Após a retirada do camarão do matapi, este é 
cozido na água e sal até que fique na cor vermelha e esteja pronto para a venda a R \$ 5,00 o litro. Furtado (2002) destaca que a Ilha do Marajó, de modo geral, tem uma efetiva pesca artesanal do camarão, assim como outros municípios no estado do Pará, que tem uma significativa contribuição na captura do camarão de água doce.

\section{'Panemeira é coisa complicada'}

A panema ou panemeira é uma expressão muito utilizada pelos mangueirenses para designar alguém que dá azar na pescaria. Esta condição de panema pode ser permanente ou temporária, sendo assim uma pessoa pode ser panema ou apenas estar panema. Para livrar-se dessa condição diversas estratégias são realizadas, como por exemplo, a realização de trabalhos com pajés, fazer banhos com pimenta malagueta, defumação ou aplicar lambada em redes e demais instrumentos de pesca. A lambada consiste em usar pião-roxo ou chama (planta local) e bater na rede, falando o desejo que se tem de afastar esse azar: "Olha rede estou te batendo para sair dessa panemeira".

\section{Mãe d'água}

Muitas questões culturais permeiam o mundo da pesca no quilombo de Mangueiras. Os mitos estão sempre presentes no cotidiano dessas pessoas para enaltecer a forte relação que esses povos mantêm com a natureza. Muitos são os relatos de histórias de pessoas 'castigadas' pela Mãe d'água ou também chamada de Mãe do Rio, estas atuando como protetoras das águas, castigando aqueles que desrespeitam o rio, seja jogando lixo ou o simples fato de falar alto ou falar palavrões. A grande observação é que a Mãe d'água se difere em algumas partes do rio. No igarapé que possui uma ponte de acesso de Deus Ajude (comunidade quilombola vizinha) a outras comunidades, a mãe d'água é um tucunaré que dizem que possui olhos vermelhos e já castigou muitos.

Já na comunidade de Mangueiras, em uma parte do rio, quem atua como protetora das águas é um tralhoto, um peixe amazônico, também conhecido como quatro-olhos, por apresentar olhos proemi- 
nentes. Geralmente fica localizado na superfície, o que mostra ainda mais fortemente a divisão dos olhos em superior e inferior, permitindo que este tenha uma visão aérea e aquática. A designação da Mãe do rio se dá através de pajés que incorporam o peixe protetor e revela para a comunidade. Os mitos cercam-se de uma cosmologia que diz que aquele que interferir no meio ambiente de forma danosa sofre as consequências, podendo chegar até a morte por afogamento ou flechada.

\section{Domínio cultural das principais espécies de peixes na comunidade}

As espécies que mostram o índice de Saliência de Smith mais elevados são as que constam como um maior consenso cultural (Caulkins \& Hyatt 1999). No quadro abaixo (Quadro 1) é possível verificar a análise do consenso cultural, a qual indica haver uma concordância nas citações de peixes no que se referem as espécies preferivelmente consumidas na comunidade quilombola de Mangueiras, cuja saliência indicou como mais elevadas o tamuatá, bacu, traíra, bagre e o aracu.

Percebe-se que a comunidade possui uma similaridade e padrões de respostas, atingindo índices de saliência para o tamuatá 0,796, bacu 0,785, traíra 0,531, bagre 0,503 e para o aracu 0,442 (ver Quadro 1). Dessa forma muitos dos dados qualitativos puderam ser vistos na apresentação e análise dos quantitativos, conforme a comunidade descreve seus conhecimentos e preferências de consumo. Os interlocutores citaram os cinco principais peixes conhecidos e consequentemente mais utilizados na alimentação.

\begin{tabular}{|l|c|c|l|c|c|}
\hline \multicolumn{1}{|c|}{ Item } & $\begin{array}{c}\text { Frequência } \\
(\%)\end{array}$ & Saliência & \multicolumn{1}{|c|}{ Item } & $\begin{array}{c}\text { Frequência } \\
(\%)\end{array}$ & Saliência \\
\hline Bacu & 85,7 & 0,785 & $\begin{array}{l}\text { Barba } \\
\text { Chata }\end{array}$ & 19 & 0,127 \\
\hline Tamuatá & 85,7 & 0,796 & Camurim & 19 & 0,036 \\
\hline Pescada & 76,2 & 0,402 & Mapara & 14,3 & 0,035 \\
\hline Traíra & 76,2 & 0,531 & Rebeca & 14,3 & 0,024 \\
\hline
\end{tabular}




\begin{tabular}{|l|c|c|l|c|c|}
\hline Bagre & 71,4 & 0,503 & Apaiari & 14,3 & 0,047 \\
\hline Aracu & 61,9 & 0,442 & Cangatá & 14,3 & 0,092 \\
\hline Piaba & 38,1 & 0,181 & Acari & 14,3 & 0,013 \\
\hline Dourada & 38,1 & 0,195 & $\begin{array}{l}\text { Branqui- } \\
\text { nha }\end{array}$ & 9,5 & 0,035 \\
\hline Filhote & 38,1 & 0,049 & Jandiá & 9,5 & 0,038 \\
\hline $\begin{array}{l}\text { Cachor- } \\
\text { rinho do } \\
\text { Padre }\end{array}$ & 28,6 & 0,148 & Tralhoto & 4,8 & 0,004 \\
\hline Jiju & 28,6 & 0,105 & Tuí & 4,8 & 0,018 \\
\hline Tucunaré & 28,6 & 0,176 & Espardate & 4,8 & 0,01 \\
\hline Sarda & 23,8 & 0,029 & Arraia & 4,8 & 0,022 \\
\hline Acará & 23,8 & 0,115 & Poraquê & 4,8 & 0,005 \\
\hline Mandubé & 23,8 & 0,079 & Pacamu & 4,8 & 0,003 \\
\hline Piranha & 23,8 & 0,074 & Pirarucu & 4,8 & 0,008 \\
\hline Pirapema & 23,8 & 0,069 & Gurijuba & 4,8 & 0,017 \\
\hline Tambaqui & 23,8 & 0,094 & Jacundá & 4,8 & 0,016 \\
\hline
\end{tabular}

Quadro 1: Índices de saliência relacionados aos peixes da comunidade de Mangueiras. Fonte: dados de campo.

As cinco primeiras mais citadas e consumidas não são vistas pela comunidade como reimosas. É importante destacar que, embora tenham citado espécies de alto valor comercial, estas não ficaram no topo das listas. Podemos levar em consideração que as espécies menos citadas muitas vezes estão atreladas a algum tabu alimentar ou são peixes que não estão com fácil acesso próximo da comunidade. Assim, são passíveis de serem encontrados nos lagos ou são peixes de baía, como são chamados pelos mangueirenses e só são encontrados no período da comidia. Essa reflexão é possibilitada pela amostra de dados quantitativos que se observa e facilmente são detectados na base de dados qualitativos. 
A pirapema, sarda, filhote, mapará e o camurim são peixes considerados muito reimosos pelos quilombolas, representando um alimento capaz de causar inflamações e dores nas pessoas, principalmente àquelas que estejam com alguma vulnerabilidade, como por exemplo, crianças, idosos, pessoas com ferimentos, mulheres menstruadas, grávidas ou no puerpério, possuíram índices de saliência bem mais próximos a zero, ou seja, não apareceram com frequência nas listas livres realizadas em Mangueiras. A piranha também foi pouco mencionada, uma vez que possui uma dualidade quando se trata de tabu alimentar, pois algumas pessoas dizem que a piranha é reimosa pelo fato de comer de tudo, enquanto outros dizem que não, já que se trata de um peixe de escama.

O pacamu foi o peixe menos mencionado e, quando referido, ainda apareceu em último na lista de consumo. Esse fato pode-se atribuir devido muitas pessoas não gostarem da aparência do peixe, pois fatores como aparência, coloração, comportamento, sabor e cheiro são critérios para determinar as escolhas alimentares, como pode ser visto no trabalho de Silva (2007) com os ribeirinhos do Médio Solimões, o qual trata das preferências e tabus. Quando questionados sobre o porquê de muita gente não consumir o pacamu, afirmaram que: "ele é um peixe feio, tem gente que não gosta”, "a cor dele é muito esquisita", "eu como qualquer coisa mas não como ele não hein, parece um sapo”. O acari, nas suas mais diversas variedades, também não é muito apreciado na comunidade, para alguns sua aparência é 'esquisita', 'estranha', para outros, tem um pitiú ${ }^{6}$ muito forte.

No entanto, mesmo muitas espécies sendo consideradas um tabu pelos atores, estas podem ser consumidas se caso a pessoa não esteja com nenhum grau de vulnerabilidade. Dessa forma, mesmo os reimosos estão inclusos na lista de peixes que são consumidos em Mangueiras. A ocorrência do consenso em muitas comunidades geralmente ocorre pelo grau de parentesco e proximidades das pessoas, que podem ocasionar similaridade no modo de vida e consequentemente o conhecimento acerca da diversidade, sendo neste caso observada na 
diversidade de peixes. Estes fatores também foram indicados por Morais et al (2009), Arruda et al (2018). Assim, as respostas quanto aos peixes preferencialmente consumidos, além das iscas e técnicas utilizadas para pescar, obedeceram a uma certa unanimidade nas respostas, o que mostra quão integradas estão as relações com esses atores.

Outro fato importante a ser observado é que os peixes de maiores valores comerciais em nenhum momento apareceram no topo da lista, o que mostra que os mangueirenses dão importância cultural a determinados peixes e que estes geralmente não possuem um alto valor para venda. Na comunidade foi possível observar, com a ajuda da lista livre, que os peixes pescados mais próximos da casa e que possuem um baixo valor comercial, são os mais apreciados para consumo, enquanto os peixes de alto valor comercial são vendidos fora da comunidade e pouco apreciados.

Peixes como a gurijuba, mandubé e o pirarucu foram citados como peixes conhecidos, no entanto, são adquiridos com menos frequência, pois geralmente estão mais acessíveis no período da comidia. O poraquê é um peixe pouco comum de ser capturado e quando ocorre é utilizado apenas na fabricação de remédio caseiro.

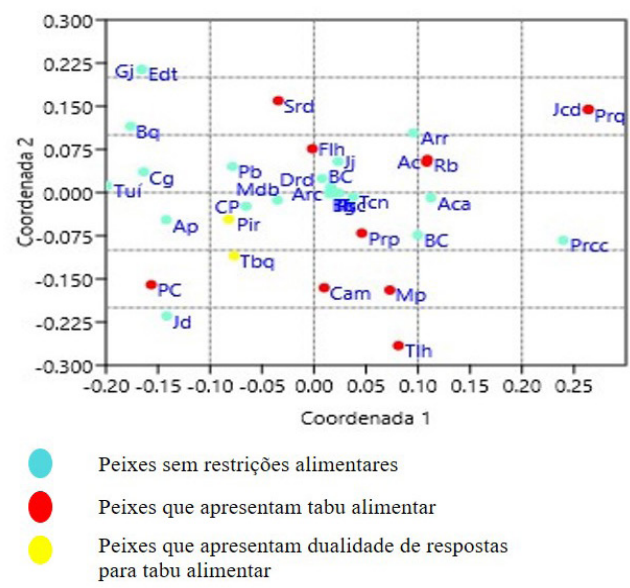

Figura 2: Consenso do domínio cultural das espécies de peixes da comunidade de Mangueiras. Fonte: dados de campo. 
A análise do escalonamento multidimensional (MDS) expõe a representação de espécies no centro da imagem (Figura 2), mostra o consenso do domínio cultural destas na comunidade. As que ficam distantes representam aquelas que foram citadas poucas vezes e como último item da lista, sendo atribuído uma menor significância. Assim, o consenso estabelecido entre as famílias quilombolas mostra um grau de similaridade significativo.

\section{Considerações finais}

Os quilombolas demonstraram uma variedade ampla de conhecimentos acerca da diversidade de espécies de peixes e mariscos que foi constantemente mencionada ou pescada pelos interlocutores, além de uma série de saberes a respeito do habitat, ciclos reprodutivos, fluxos migratórios e alimentação dessas espécies, o que permite uma melhor localização da ictiofauna, possibilitando a definição de técnicas adequadas para a captura dos recursos pesqueiros com maior facilidade e no período favorável.

A metodologia empregada serviu para mostrar que há um consenso cultural acerca das espécies de peixes contidas na lista livre, outro ponto também observado é a similaridade de resposta em se tratando das práticas aplicadas na pesca. Além disso, a comunidade apresenta uma dinâmica interessante quando se trata de organização e participação familiar nas atividades produtivas, sendo mais específica na pescaria e mariscagem, assim como também se organizam e compartilham o pescado capturado entre as equipes de pesca e seus familiares.

Aos poucos as práticas e os apetrechos utilizados foram sendo readaptados ou mesmo trocados. Antes a maioria dos apetrechos era confeccionado na própria comunidade, hoje, embora os quilombolas ainda confeccionem instrumentos de trabalhos, esse número reduziu se considerarmos a produção dos 'tempos antigos'. Atualmente, os apetrechos são modelos mais modernos e facilmente adquiridos na cidade. 
Os conhecimentos tradicionais foram sendo transmitidos de geração a geração, no que se refere aos procedimentos adotados nas lógicas produtivas familiares. A convivência com os rios e lagos da comunidade fazem com que consigam dominar as práticas de acesso ao recurso pelo fato de muito cedo observarem as estratégias necessárias na captura das espécies e, assim, desenvolvem uma habilidade importante e característica desse povo na forma como usam e manejam a biodiversidade.

\section{Notas:}

1 O ato de boquejar pelo bagre caracteriza-se quando o peixe vem até a superfície em cardume e fica com a boca exposta.

2 Tipo de pesca que é realizado com um tapume, ou seja, um tipo de cerca com varas de bambu ou açaizeiro, sendo as varas chamadas de cambitos; nestes são colocadas as redes para fechar todo o furo (um curso d'água) e encurralar os peixes.

3 Cambada é uma porção de peixes que ficam pendurados em um cordão ou cipó ou embira (cordão feito da casca de árvores ou outro tipo de fibra vegetal). Este procedimento facilita o transporte do pescado até a casa ou feiras e comércios, quando os pescadores saem para vender o pescado.

4 Bubuia é uma expressão utilizada para explicar uma técnica de pesca que é realizada com a rede. Nesse caso pegar a dourada de bubuia é quando o pescador não coloca peso na rede, ou seja, nas pontas onde geralmente se usa pedra para que a rede afunde, não se coloca nada. A rede não afunda completamente e os pescadores vêm arrastando-a de forma que siga a rotação da maré e assim capture os peixes, sendo que os pescadores afirmam, na parte do rio próximo à comunidade, ser mais fácil pegar dourada com essa técnica.

5 Prato típico preparado em Mangueiras feito com o vinho do tucumã e adicionase dois sararás, temperos e carnes.

6 Termo usado na região Norte para determinar cheiro forte de algo, por exemplo, de peixe, ou simplesmente, caracteriza mau cheiro.

\section{Referências:}

ALBUQUERQUE, U., LUCENA, R. \& CUNHA, L. 2010. "Métodos e técnicas de coleta de dados etnobiológicos". In ALBUQUERQUE, U. \& LUCENA, R. (eds.): Métodos e técnicas na pesquisa etnobiológica e etnoecológica, pp. 41-64. Recife: Ed. NUPPEA. 
ALENCAR, Edna. 2014. "Questões de Gênero em Projetos de Manejo de Recursos Pesqueiros na Reserva de Desenvolvimento Sustentável Mamirauá". In LEITÃO, M. (ed.): Pesca, turismo e meio ambiente, pp. 123-143. Recife: EDUFRPE.

ALENCAR, E. \& SOUSA, I. 2017. "Aspectos Socioambientais da Pesca Manejada de Pirarucus (Arapaima gigas) no Sistema de Lagos Jutai-Cleto”, Reserva de Desenvolvimento Sustentável Mamirauá, AM". Amazônica: Revista de Antropologia, 9(1):36-71.

ALONSO-POBLACIÓN, E. 2014. O mar é femia. Riesgo y trabajo entre los pescadores de una villa costera gallega. Madrid: Ministerio de Educación, Cultura y Deporte.

ARRUDA, J. et al. 2018. "Conhecimento ecológico tradicional da ictiofauna pelos quilombolas no Alto Guaporé, Mato Grosso, Amazônia meridional, Brasil”. Boletim do Museu Paraense Emílio Goeldi. Ciências Humanas, 13(2):315329.

BARBOZA, R. \& PEZZUTI, J. 2011. "Etnoictiologia dos pescadores artesanais da Resex Marinha Caeté-Taperaçu, Pará: aspectos relacionados com etologia, usos de hábitat e migração de peixes da família Sciaenidae”. Sitientibus série Ciências Biológicas, 11(2):133-141.

BARROS, Flávio. 2012. "Etnoecologia da pesca na Reserva Extrativista Riozinho do Anfrísio-Terra do Meio, Amazônia, Brasil”. Amazônica: Revista de Antropologia, 4(2):286-312.

BEGOSSI, Alpina. 1992. "Food taboos at Buzios Island (Brazil): their significance and Telanon to folk medicine”. Journal of Ethnobiology, 12(1):117-139.

BEGOSSI, A. \& FIGUEIREDO, J. L. 1995. "Ethnoichthyology of southern coastal fishermen: cases from Búzios Island and Sepetiba Bay (Brazil)”. Bulletin of Marine Science, 56(2):710-717.

BELTRÃO, H. \& SOARES, M. G. 2018. "Variação temporal na composição da ictiofauna do lago e igarapés da Reserva de Desenvolvimento Sustentável Tupé na Amazônia Central". Biota Amazônia (Biote Amazonie, Biota Amazonia, Amazonian Biota), 8(1):34-42.

BERNARD, Harvey. 1988. Research methods in cultural anthropology. Newbury Park: Sage.

BRASIL. 2007. Política Nacional de Desenvolvimento Sustentável dos Povos e Comunidades Tradicionais (PNPCT), Decreto Presidencial No 6.040-2007 de 07 de fevereiro de 2007.

BRUMER, A. et al. 2008. "A elaboração de projeto de pesquisa em ciências sociais”. In GUAZZELLI, C. \& PINTO, C. (eds.). Ciências humanas: pesquisa e método, pp. 125-147. Porto Alegre: UFRGS.

CLAUZET, M., RAMIRES, M. \& BARRELLA, W. 2005. « Pesca artesanal e conhecimento local de duas populações caiçaras (Enseada do Mar Virado e Barra do Una) no litoral de São Paulo, Brasil”. Multiciência, 4(1):1-22. 
COSTA-NETO, Eraldo. 2000. "Restrições e preferências alimentares em comunidades de pescadores do município de Conde, Estado da Bahia, Brasil”. Revista de Nutrição, 13(2):117-126.

COSTA-NETO, E. \& MARQUES, J. G. 2000. "Conhecimento ictiológico tradicional e a distribuição temporal e espacial de recursos pesqueiros pelos pescadores de Conde, Estado da Bahia, Brasil”. Etnoecológica, 4(6):56-68.

DIEGUES, Antonio. 2004. A pesca construindo sociedades. São Paulo: NUPAUB. 1988. Pesca artesanal no litoral brasileiro: cenários e estratégias para a sua sobrevivência. São Paulo: Instituto Oceanográfico.

1983. Pescadores, camponeses e trabalhadores do mar. São Paulo: Editora CEMAR-USP.

FARIAS, Márcia. 2001. Pesca e sazonalidade no Camacho/SC: um estudo de modos de vida em deslocamento. Dissertação de Mestrado. Florianópolis: UFSC.

FURTADO, Lourdes G. 2006. "Origens pluriétnicas no cotidiano da pesca na Amazônia: contribuições para projeto de estudo pluridisciplinar". Boletim do Museu Paraense Emílio Goeldi. Ciências Humanas, 1(2):159-172.

GEERTZ, Clifford. 1989. A Interpretação das Culturas. Rio de Janeiro: Zahar.

GOULDING, Michael. 1980. The fishes and the forest: explorations in Amazonian natural history. Berkeley: University of California Press.

HAHN, N., ALMEIDA, V. \& LUZ, K. 1997. "Alimentação e ciclo alimentar diário de Hoplosternum littorale (Hancock) (Siluriformes, Callichthyidae) nas lagoas Guaraná e Patos da Planície do Alto Paraná, Brasil”. Revista Brasileira de Zoologia, 14(1):57-64.

JUNK, Wolfgang. 1983. "A ictiofauna da Região Amazônica". In Salati, E. et al. (eds.): Amazônia: Desenvolvimento, Integração e Ecologia, pp. 45-100. Brasília: Editora Brasiliense.

LOWE-MCCONNELL, Rosemary. 1987. Ecological Studies in Tropical Fish Communities. Cambridge University Press.

MACHADO, Denise. 2007. "Catadoras de caranguejo e saberes tradicionais na conservação de manguezais da Amazônia brasileira”. Estudos Feministas, 15(2):485-490.

MARQUES, José Geraldo. 1991. Aspectos ecológicos na etnoictiologia dos pescadores do complexo estuarino-lagunar Mandau-Manguaba, Alagoas. Tese de Doutorado. Campinas: UNICAMP.

. 2001. Pescando pescadores: ciência e etnociência em uma perspectiva ecológica. São Paulo: NUPAUB/USP.

MIRANDA, W. \& CRESCÊNCIO, R. 2008. Reprodução do tamoatá (Hoplosternum littorale) por manipulação ambiental. Trabalho apresentado na Jornada de Iniciação Científica da Embrapa Amazônia Ocidental, 3, Manaus-AM.

MURRIETA, Rui. 2001. "A mística do Pirarucu: pesca, ethos e paisagem em comunidades rurais do baixo Amazonas". Horizontes Antropológicos, 7:16):113130. 
NAZAREA, Virginia. 1999. "Introduction. A view from a point: Ethnoecology as situated knowledge”. In NAZAREA, V. (ed.): Ethnoecology: situated knowledge/located lives. Editado por Virginia Nazarea, pp. 3-20. Arizona: The University of Arizona Press.

OLIVEIRA, J. \& FREITAS, J. 1996. “Toxicidade de peixes tetraodontídeos (Osteichthyes, Teleostei): dados preliminares". Trabalho apresentado no Simpósio de Biologia Marinha, São Sebastião-SP.

PAZ, V. \& BEGOSSI, A. 1996. "Ethnoichthyology of Gaiviboa fishermen of Sepetiba bay, Brazil". Journal of Ethnobiology, 16(2):157-168.

PRADO, D. et al. 2017. "Preferências, tabus alimentares e uso medicinal de peixes na reserva de desenvolvimento sustentável Barra do Una, São Paulo". Ethnoscientia, 2(1):1-15.

RAMIRES, M., MOLINA, S. \& HANAZAKI, N. 2007. "Etnoecologia Caiçara: o conhecimento dos pescadores artesanais sobre aspectos ecológicos da pesca". Biotemas, 20(1):101-113.

ROMNEY, A. \& WELLER, S. 1984. "Predicting informant accuracy from patterns of recall among individuals". Social Networks, 6(1):59-77.

SÁ-OLIVEIRA, J. \& CHELLAPPA, S. 2002. "Fecundidade e tipo de desova do tamuatá, Hoplosternum littorale Hancock (Osteichthyes, Siluriformes) no Rio Curiaú, Macapá, Amapá”. Revista Brasileira de Zoologia, 19(4):1053-1056.

SABOURIN, Eric. 2008. "Marcel Mauss: da dádiva à questão da reciprocidade". Revista Brasileira de Ciências Sociai, 23(66):131-139.

SANTOS, L., GONZALEZ, A. \& ARAÚJO, F. 2001. "Dieta do tucunaréamarelo Cichla monoculus (Bloch \& Schneider) (Osteichthyes, Cichlidae), no reservatório de Lajes, Rio de Janeiro, Brasil”. Revista Brasileira de Zoologia, 18(1):191-204.

SAUTCHUK, Carlos Emmanuel. 2007. O arpão e o anzol: Técnica e pessoa no estuário do Amazonas (Vila Sucuriju, Amapá). Tese de Doutorado. Brasília: UNB.

SILVA, Andréa. 2007. "Comida de gente: preferências e tabus alimentares entre os ribeirinhos do Médio Rio Negro (Amazonas, Brasil)”. Revista de Antropologia, 50(1):125-179.

SILVANO, Renato. 1997. Ecologia de três comunidades de pescadores do rio Piracicaba (SP). Dissertação de Mestrado. Campinas: UNICAMP.

TOLEDO, Victor. 1992. "What is ethnoecology? Origins, scope and implications of a rising discipline”. Etnoecológica, 1(1):5-21.

TOLEDO, V. \& BARRERA-BASSOLS, N. 2009. "A etnoecologia: uma ciência pós-normal que estuda as sabedorias tradicionais”. Desenvolvimento e Meio Ambiente, 2(20):31-45.

VAZZOLER, Anna. 1996. Biologia da reprodução de peixes teleósteos: Teoria e prática. Maringá: EDUEM/SBI. 


\begin{abstract}
This work was developed in the quilombola community of Mangueiras, Ilha do Marajó (Pará), with the objective of characterizing the fishery resources of food importance and the practices used in artisanal fishing, as well as the sociabilities that involve this activity, and also to demonstrate the domain cultural community about fishing. We interviewed 21 fisherwomen and fishermen to prepare the free fish list. We used open and semi-structured interviews, participant observation, guided tours by local fishermen and the free listing technique. For free list analisa we use the Smith salience index. The results showed that fishermen and fisherwomen maintain a constant transmission of knowledge, provedes through daily contanto with fish and the river since childhood. Traditional knowledge is part of the identity and culture of the quilombo, a territory dominated by social actors who are constantly familiar with Théo ichthyofauna, distinguishing them by their habitat, food preferencias and reavio.
\end{abstract}

Keywords: Sociobiodiversity, Artisanal fishing, Culture, Amazon.

Recebido em julho de 2020.

Aprovado em março de 2021. 